\title{
Agriculture
}

Research Direction générale

Branch de la recherche

Technical Bulletin 1984-3E

\section{Construction details
a large forage plot harvester for cleanup \\ and harvest of test plots}

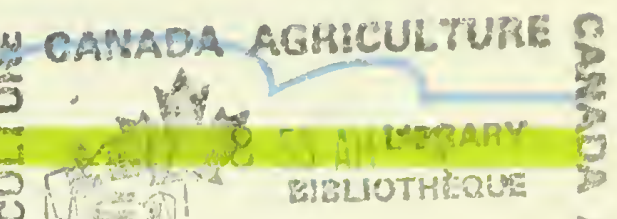

e

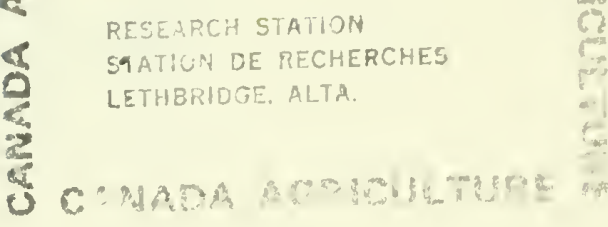


The map on the cover has dots representing Agriculture Canada research establishments. 


\section{Construction details of a large forage plot harvester for cleanup and harvest of test plots}

RAYNALD DRAPEAU and ULYSSE DALLAIRE Experimental Farm

Normandin, Quebec

Report No. 216, Sainte-Foy Research Station, Quebec

Research Branch

Agriculture Canada

1984 
(i)per of this publication ane araifable from:

Evprumentul Form

Rescamb Btanch. Igrioultume Cantuda

Hizume st-Cirille

Vimandm, Quelec

(;0W '? 0

Prexhued by Renearch Proglan Service

- Monster of Supply and Services Camala 1984 Cilt. No. A5t-8 1984-3E

ISB. $0-662-13032-4$

Auni elivpunible en français sous le titte Délauls de construction d'une grosse fourragère pour le nelloyage el la iécolle de parcelles 
CONTENTS

Abstract $\ldots \ldots \ldots \ldots \ldots \ldots \ldots \ldots \ldots \ldots \ldots \ldots \ldots \ldots \ldots \ldots \ldots \ldots \ldots \ldots$

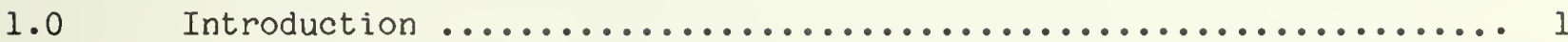

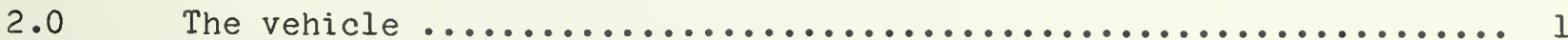

2.1 The motor $\ldots \ldots \ldots \ldots \ldots \ldots \ldots \ldots \ldots \ldots \ldots \ldots \ldots \ldots \ldots \ldots \ldots \ldots \ldots \ldots \ldots$

2.2 The transmission $\ldots \ldots \ldots \ldots \ldots \ldots \ldots \ldots \ldots \ldots \ldots \ldots \ldots \ldots \ldots \ldots \ldots \ldots \ldots$

$2.3 \quad$ The wheels $\ldots \ldots \ldots \ldots \ldots \ldots \ldots \ldots \ldots \ldots \ldots \ldots \ldots \ldots \ldots \ldots \ldots \ldots \ldots \ldots \ldots \ldots$

2.4 The cutter control $\ldots \ldots \ldots \ldots \ldots \ldots \ldots \ldots \ldots \ldots \ldots \ldots \ldots \ldots \ldots \ldots \ldots \ldots$

2.5 The hydraulic system $\ldots \ldots \ldots \ldots \ldots \ldots \ldots \ldots \ldots \ldots \ldots \ldots \ldots \ldots \ldots \ldots \ldots$

2.6 The cutter $\ldots \ldots \ldots \ldots \ldots \ldots \ldots \ldots \ldots \ldots \ldots \ldots \ldots \ldots \ldots \ldots \ldots \ldots \ldots \ldots \ldots$

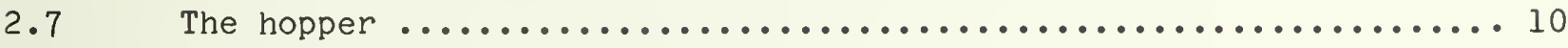

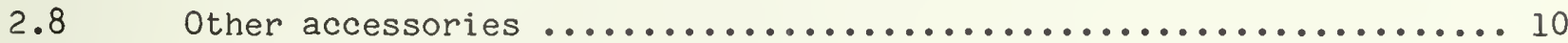

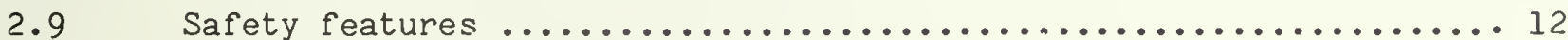

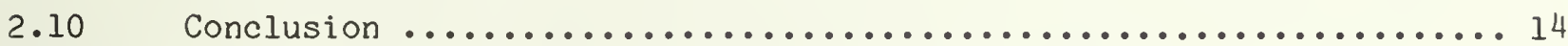

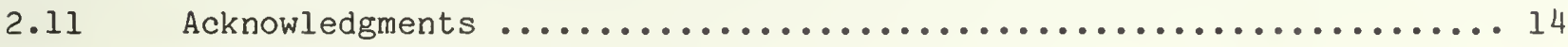




\section{Abstract}

This technical bulletin provides construction details for a large forage plot harvester built specifically to clean up experimental plots and to take samples on large plots for experimental purposes.

\section{Résumé}

Le bulletin technique présente les détails de construction d'une grosse fourragère construite spécifiquement pour le nettoyage des parcelles expérimentales et/ou pour la prise d'échantillons lorsque de grandes parcelles sont requises pour atteindre les objectifs expérimentaux. 
To conduct forage experiments, whether they involve cultivar evaluation or management studies, test plots have to be planted and tended for several years. Replication of seedings over 2 or 3 consecutive years increases the number of plots that must be cut and the area that must be restored to an identical condition after removal of the samples used to determine yields or other agronomic characteristics. Cleanup of the test area after sampling takes a relatively long time with small forage plot harvesters, but large machines are very inconvenient to use for this work. For these reasons, it was decided to construct a large forage plot harvester that was compact, easy to operate, and labor efficient, and that saved time.

There are no plans for the forage plot harvester. The purpose of this bulletin is to provide a reasonably detailed description of the main components and their operation.

\section{0 - THE VEHICLE}

The forage plot harvester is $127.5 \mathrm{~cm}$ wide by $232.5 \mathrm{~cm}$ long. The frame of the harvester (Fig. 1) is made of square tubes, $5 \times 10 \times 0.5 \mathrm{~cm}(2 \times 4 \times 3 / 16$ inch), bent and welded into a rectangular shape, ending in a point. The chassis is $120 \mathrm{~cm}$ long by $47.5 \mathrm{~cm}$ wide. Pieces "d" and "e" (Fig. 1) reinforce the frame and support other parts of the machine. Point "a" shows the location of the front wheel axle, $23.7 \mathrm{~cm}$ from the front of the frame. The steering linkage arm is inserted at point "b" (Fig. 1). The front part of the forage harvester pivots on shaft "c", which is $3.2 \mathrm{~cm}$ in diameter, by means of two pillow blocks. The shaft also carries the sprockets that transmit power from the transmission to the front wheels by a chain drive.

The structure of the mobile frame of the forage harvester is shown in Figure 2. The cutter is attached to the mobile subframe on piece "f" using bolts $12 \times 89 \mathrm{~mm}(1 / 2 \times 31 / 2$ inches). The two pieces "g" support the hopper, and plates "h" secure the front part of the harvester to the shaft "c" (Fig. 1) by means of pillow blocks. A metal plate $19 \mathrm{~mm}(3 / 4 \mathrm{inch})$ thick is fitted between the pillow blocks and the plates "h" so that the coupling point of the cutter projects $5 \mathrm{~cm}$ beyond the chassis of the vehicle. The hydraulic cylinder that lifts the front of the forage harvester is attached at one end to a point between the metal plates "k" (Fig. 2) and at the other to the support "e" on the frame of the vehicle (Fig. 1). The lower part of the cylinder that is used to empty the hopper is attached to point " $n$ " on the mobile subframe.

\section{1 - THE MOTOR}

The motor is mounted on a support that protrudes slightly from the frame at the right rear. The motor is a Briggs and Stratton 16 horsepower two-cylinder air-cooled gas motor. The electric starter, the generator, and the alternator are integral with the motor. The throttle is connected through a cable to a remote control located near the operator's seat. 


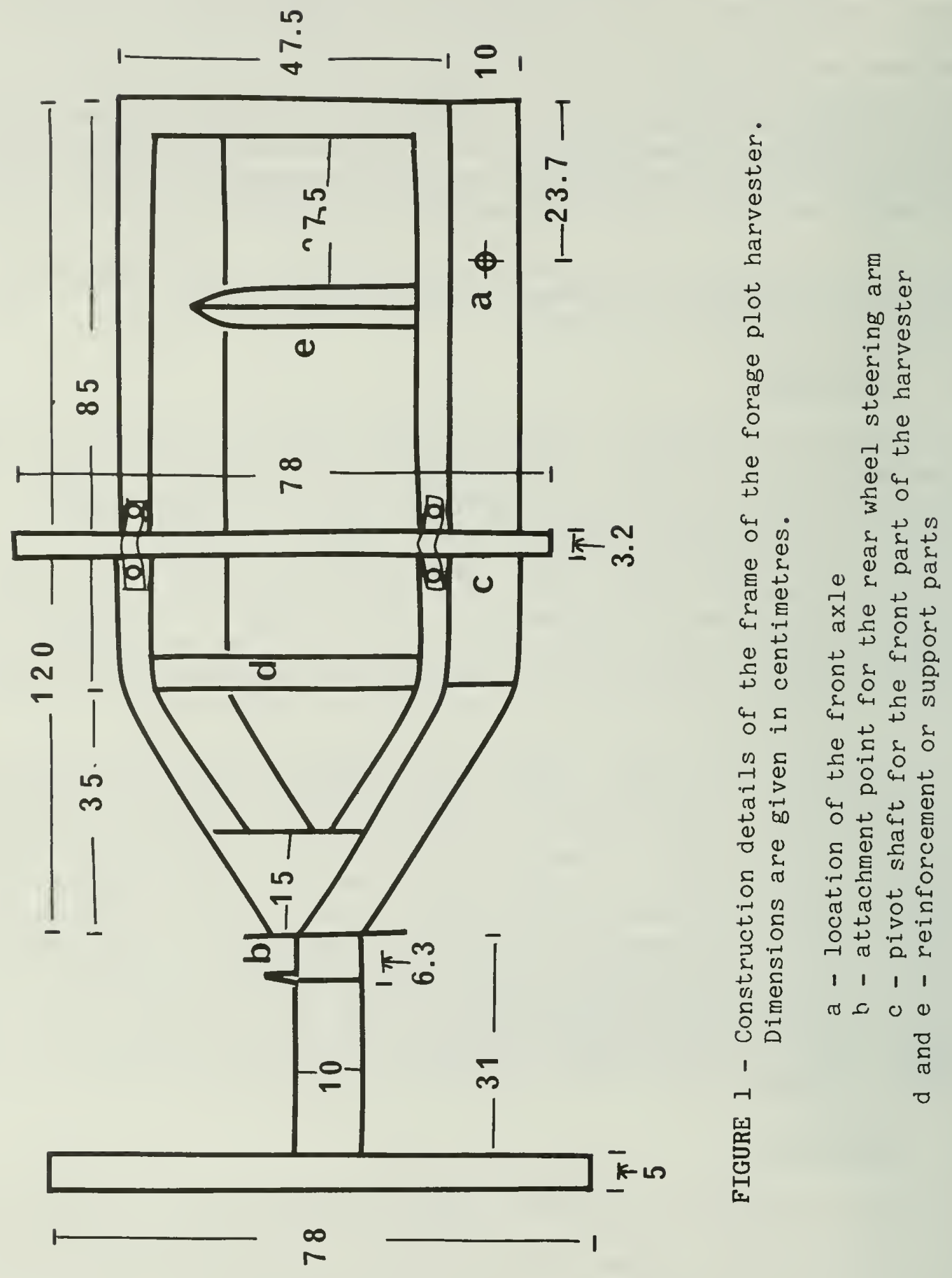




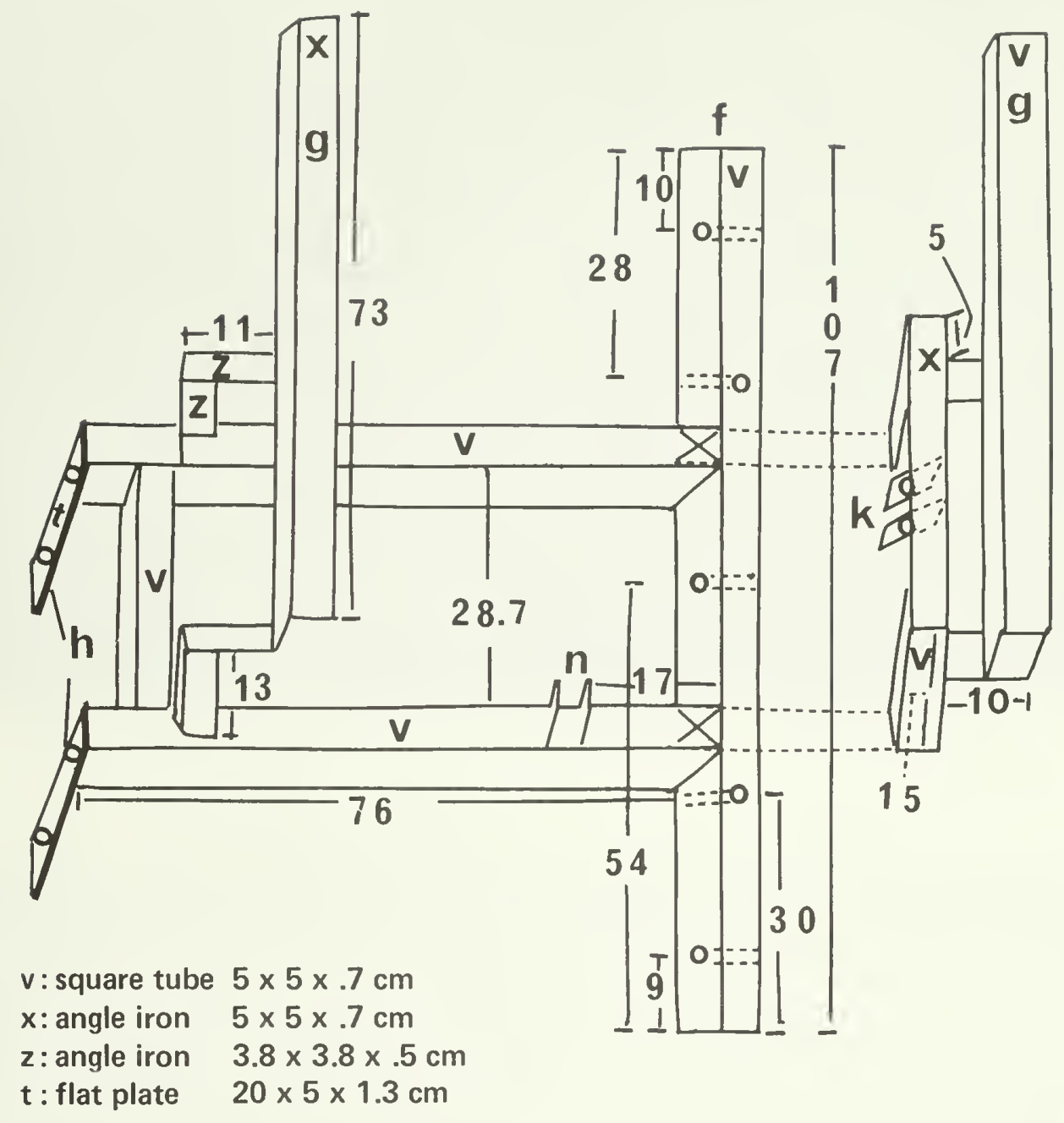

FIGURE 2 - Construction details of the subframe of the mobile front portion of the forage harvester. Dimensions are given in centimetres.

f - cutter attachment points

g - hopper support

h - attachment of the mobile subframe to the shaft using pillow blocks

$k$ - attachment of cylinder that lifts the front of the forage harvester

$\mathrm{n}$ - attachment of the base of the cylinder that tips up the hopper 


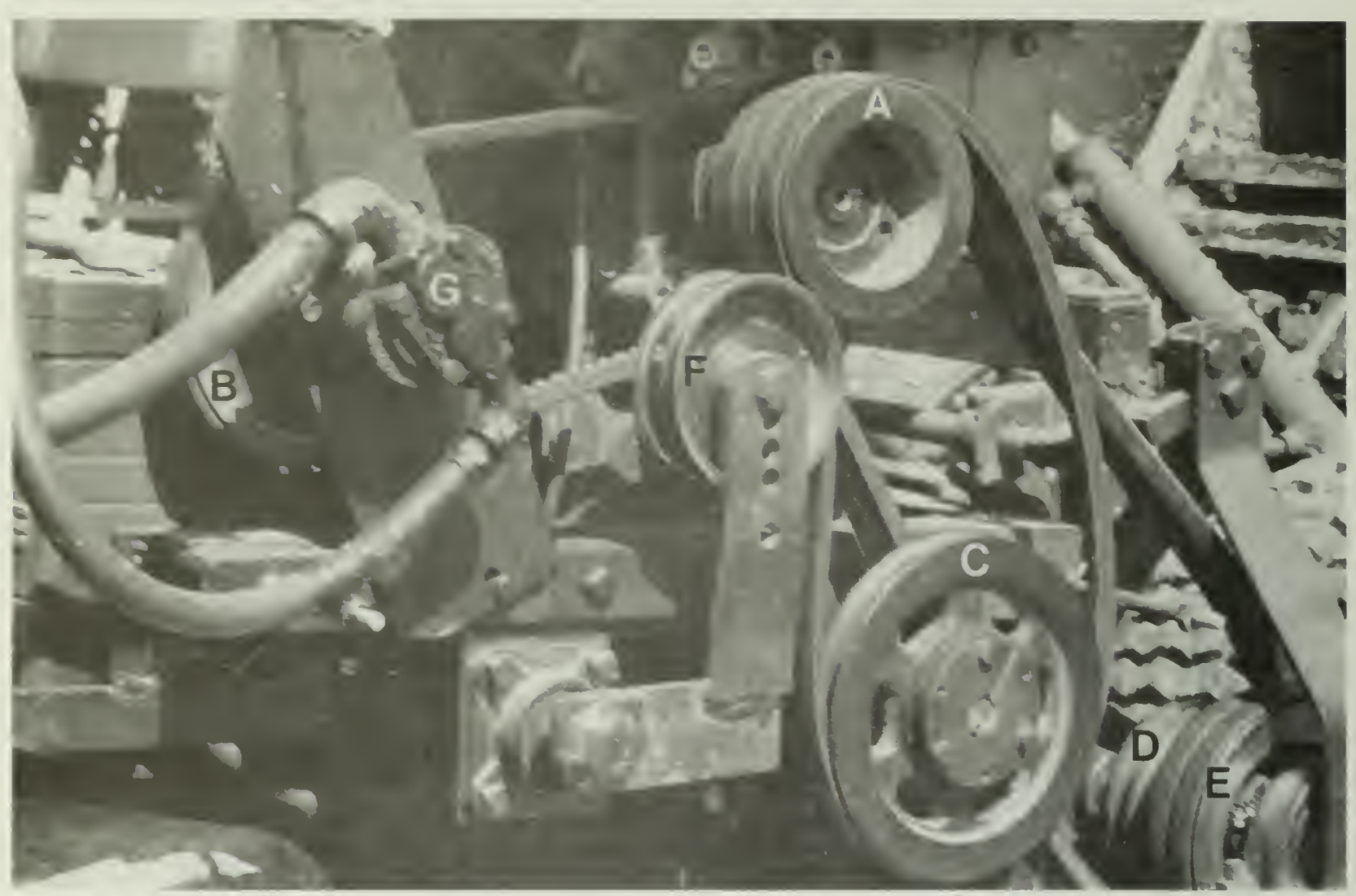

FIGURE 3 - Mechanism for transmission of power from the motor to the accessories.

Power is transmitted to accessories by belts from the four-belt pulley A (Fig. 3) fixed to the power takeoff shaft. The pulley is $12.8 \mathrm{~cm}$ ( 5 inches) in diameter, with a $2.5 \mathrm{~cm}$ ( 1 inch) shaft size. The innermost belt is connected to pulley B (Fig. 3), which is a single-belt pulley $15.3 \mathrm{~cm}$ ( 6 inches) in diameter with a shaft size of $1.25 \mathrm{~cm}$ ( $1 / 2$ inch). This pulley powers the hydraulic system pump $G$. The two central belts go to pulley $D$ of the DE complex (Fig. 3), which consists of two two-belt pulleys with diameters of 12.8 and $15.3 \mathrm{~cm}$ ( 5 and 6 inches), respectively. These pulleys transmit motive power to the cutter. The fourth belt, on the outside, is connected to a single-belt pulley C (Fig. 3) $17.8 \mathrm{~cm}$ ( 7 inches) in diameter and shaft size of $2.5 \mathrm{~cm}$ ( 1 inch), which provides power to the transmission.

\section{2 - THE TRANSMISSION}

The transmission is a Peerless No. 2302A complete with a clutch control. It is attached to the triangular part of the frame of the vehicle and has three forward speeds and one reverse.

A $5 \mathrm{~L}-430 \mathrm{~V}$-belt runs hetween the motor and the transmission. Tension is controlled through an idler pulley F (Fig. 3) acting as a clutch. The idler pulley is operated by a pedal (Al, Fig. 9) on the footrest, connected by a steel rod. The clutch pedal engages the transmission when it is pushed down. 


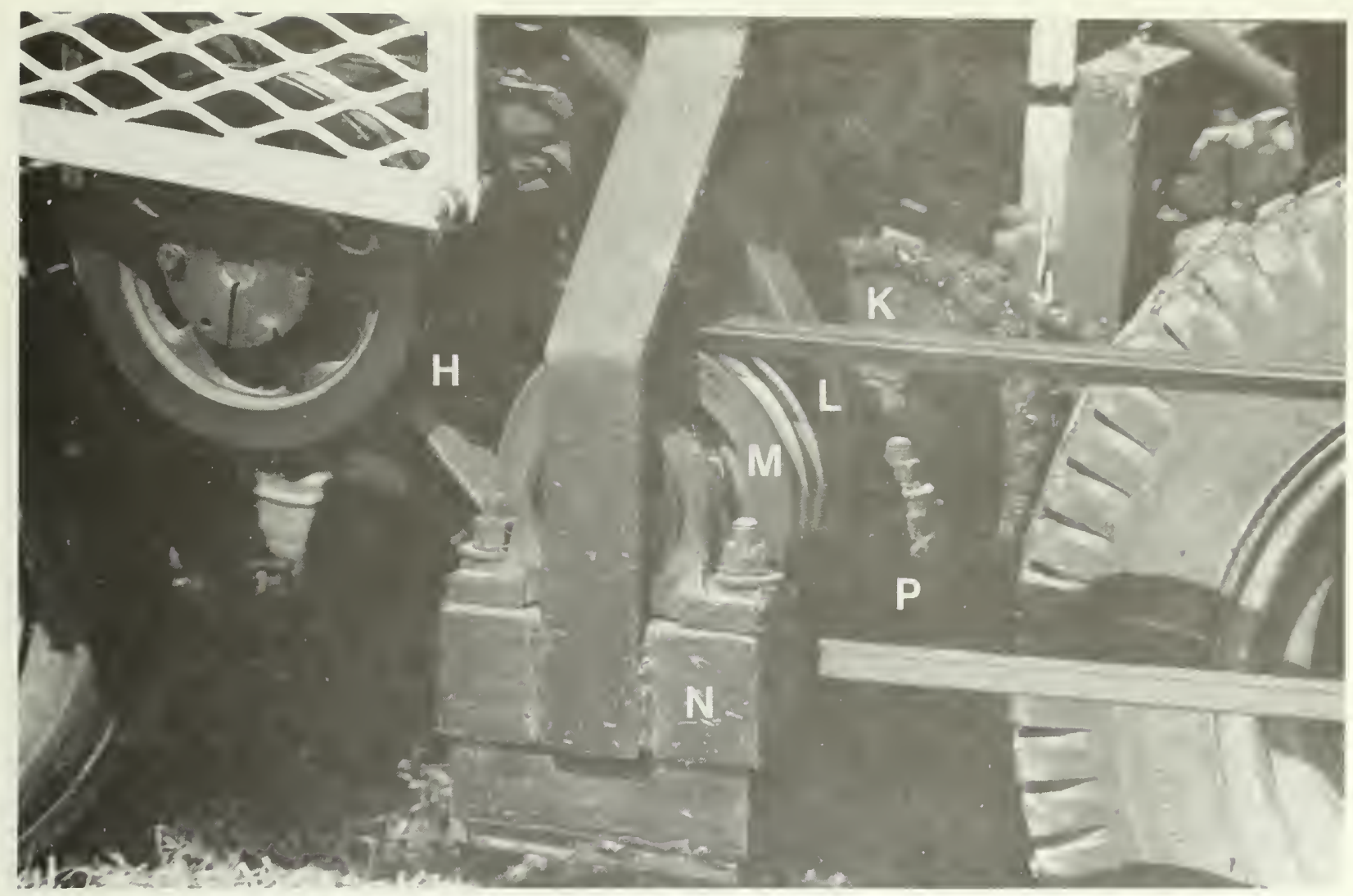

FIGURE 4 - Control system for the drive and for power transfer to the cutter.

To change gears, the clutch is disengaged by taking one's foot off the pedal, which returns to its original position by means of a spring. The speed control is then set in the desired position and the operator presses on the pedal to engage the clutch.

Independent drive on each wheel is obtained through a No. 50 chain system. A power sprocket $\mathrm{H}$ (Fig. 4) with 26 teeth and $2.5 \mathrm{~cm}$ ( 1 inch) shaft size is attached to the transmission shaft and connected to the KJ complex by a chain. Tension on the chains is maintained through an adjustable gear wheel attached partly under the motor support and partly under the footrest. The KJ complex consists of two pulleys with 36 and 30 teeth respectively and with a shaft size of $3.2 \mathrm{~cm}$ ( 1 1/4 inch). A grease coupling between the two sprockets provides lubrication. The KJ complex transmits power from the transmission to a 30-tooth sprocket welded to the center of the front wheel. This system is used again for each of the axles. (This concept is based on an unpublished design by G. B. Hergert, Engineering and Statistical Research Service, Agriculture Canada, Ottawa.) 


\subsection{THE WHEELS}

The front tires are 57.5 - $21.25-30 \mathrm{~cm}(23-8.5-12$ inches), whereas the steering tires are $41.25-16.25-20 \mathrm{~cm}(16.5-6.5-8$ inches). A major modification should be made to the front wheels. The center of the wheel rim should be unwelded and reconnected to the interior edge of the rim in order to clear the sprocket welded to the hub of the wheel and allow the chain to go around without rubbing against the tire.

\section{4 - THE CUTTER CONTROL}

The cutter control system originally consisted of two large belts that directly connected the power take-off of the motor to the cutter pulley. This system was changed after one season of tests, because the rotation of the cutter could not be kept constant as a result of loss of tension on the belts when the front part of the forage harvester was raised to make a higher cut. To counteract this major inconvenience and the resulting loss of efficiency, the system that transfers power from the motor to the cutter was modified and operates with the help of a neutral point located in the same axis as the pivot shaft of the front part of the vehicle.

The neutral point also acts as the attachment point for the clutch mechanism of the cutter. This consists of two steel boxes, N and P (Fig. 4), which slide on two metal blocks. Movement of the boxes downward increases tension on two belts, which are connected to the motor and provide rotary motion to the cutter. The inverse movement stops the cutter rotation. The whole mechanisn is engaged by means of a metal har located near the steering wheel of the vehicle and connected by a rod V (Fig. 8).

The clutch block of the cutter, made up of two pulleys $M$ and L (Fig. 4), with double belts and diameters of 15.3 and $12.8 \mathrm{~cm}$ ( 6 and 5 inches) respectively, makes it possible to alter the rotary speed of the cutter by changing pulley $M$ or L to a smaller or larger diameter depending on whether a reduction or increase of maximum speed is desired. In addition, depending on requirements, installing the system at a neutral point provides a way of adjusting the cutting height without loss of rotary power to the cutter. A double-belt pulley of $21.25 \mathrm{~cm}$ ( 8.5 inches) diameter, fixed on the axis of the cutter, completes the system.

\section{5 - THE HYDRAULIC SYSTEM}

One hydraulic system is used to operate four cylinders. All the components are connected by flexible hydraulic hose of medium pressure.

The power steering consists simply of a steering control mechanism at the base of the steering column and a hydraulic cylinder Q (Fig. 5) that can stretch

$19 \mathrm{~cm}$ ( 7.5 inches). The system was taken from the power steering used on some models of Ford cars. The steering control and the cylinder are connected by a flexible hydraulic hose to a reservoir $\mathrm{R}$, which is a rectangular column with a capacity of $2.5 \mathrm{~L}$. 


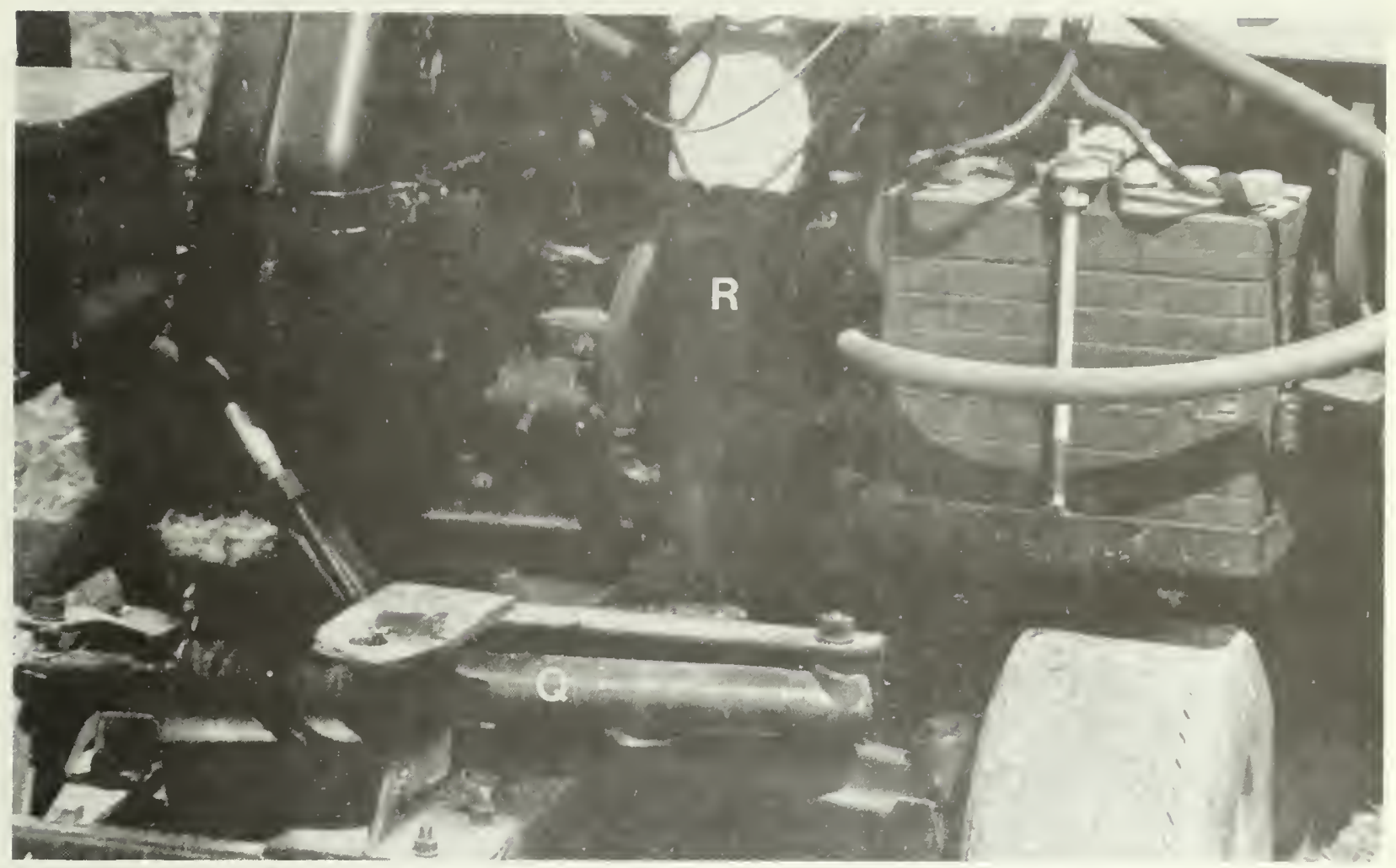

FIGURE 5 - Part of the hydraulic system used for power steering.

Cylinders S and T (Fig. 6) empty the hopper and raise the front part of the forage harvester, respectively. These two cylinders are $37.5 \mathrm{~cm}$ ( 15 inches) long and $2.5 \mathrm{~cm}$ ( 1 inch) in diameter and have a maximum stretch of $25 \mathrm{~cm}$ (10 inches).

One end of cylinder $S$ is connected to the mobile subframe at point "n" (Fig. 2), and the other end is connected to the hopper $37.5 \mathrm{~cm}$ (15 inches) from the end of it. The bottom of the hopper is fastened to the mobile frame by a large hinge. Cylinder $\mathrm{T}$ is attached at one end to bar "e" (Fig. 1) welded to the vehicle frame and at the other end to the front of the machine between the steel plates "k" (Fig. 2). Two springs U (Fig. 6) were installed under the mobile subframe of the forage harvester to allow the cutter to follow the terrain more closely and to provide better traction for the wheels by shifting the weight of the mobile part to the frame of the vehicle.

The final component of the hydraulic system consists of a cylinder $60 \mathrm{~cm}$ ( 24 inches) long with a diameter of $2.5 \mathrm{~cm}$ ( 1 inch) having a stretch of $40 \mathrm{~cm}$ (16 inches). One end is connected to the hopper and the other end to the hopper gate. This cylinder opens and closes the hopper gate (Fig. 7). The oil pressure necessary to activate all the components of the hydraulic system is provided by pump G (Fig. 3). 


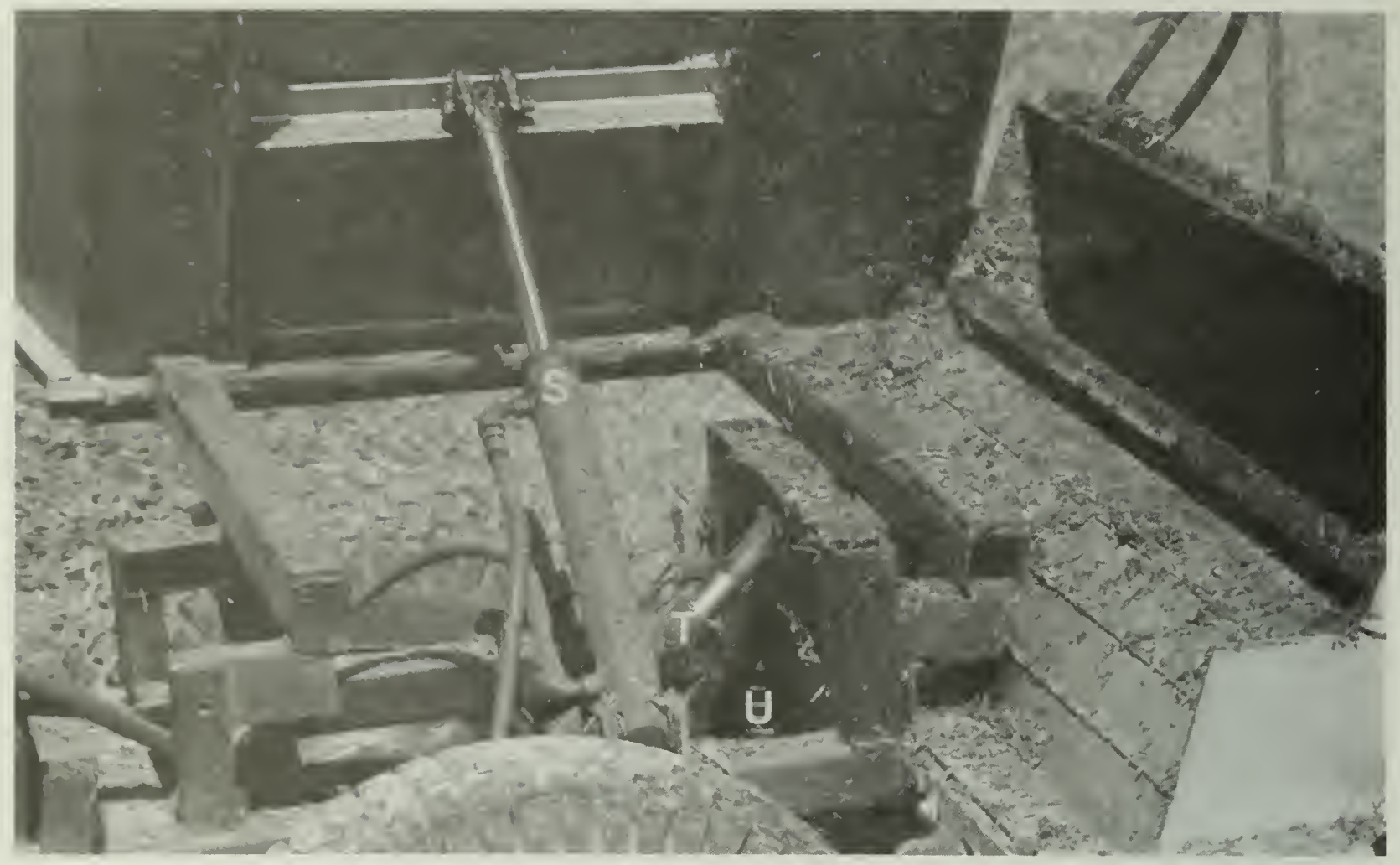

FIGURE 6 - Components of the hydraulic system that lifts the front part of the vehicle and empties the hopper.

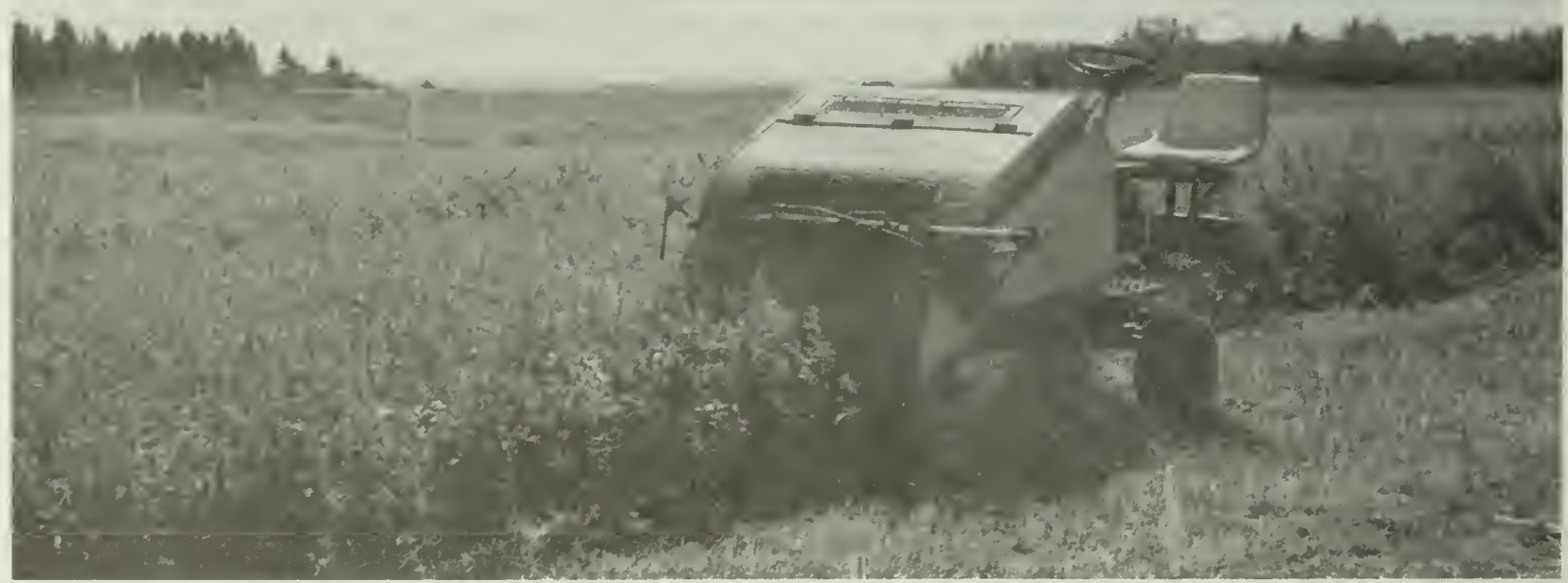

FIGURE 7 - Components of the hydraulic system that opens the hopper for emptying. 


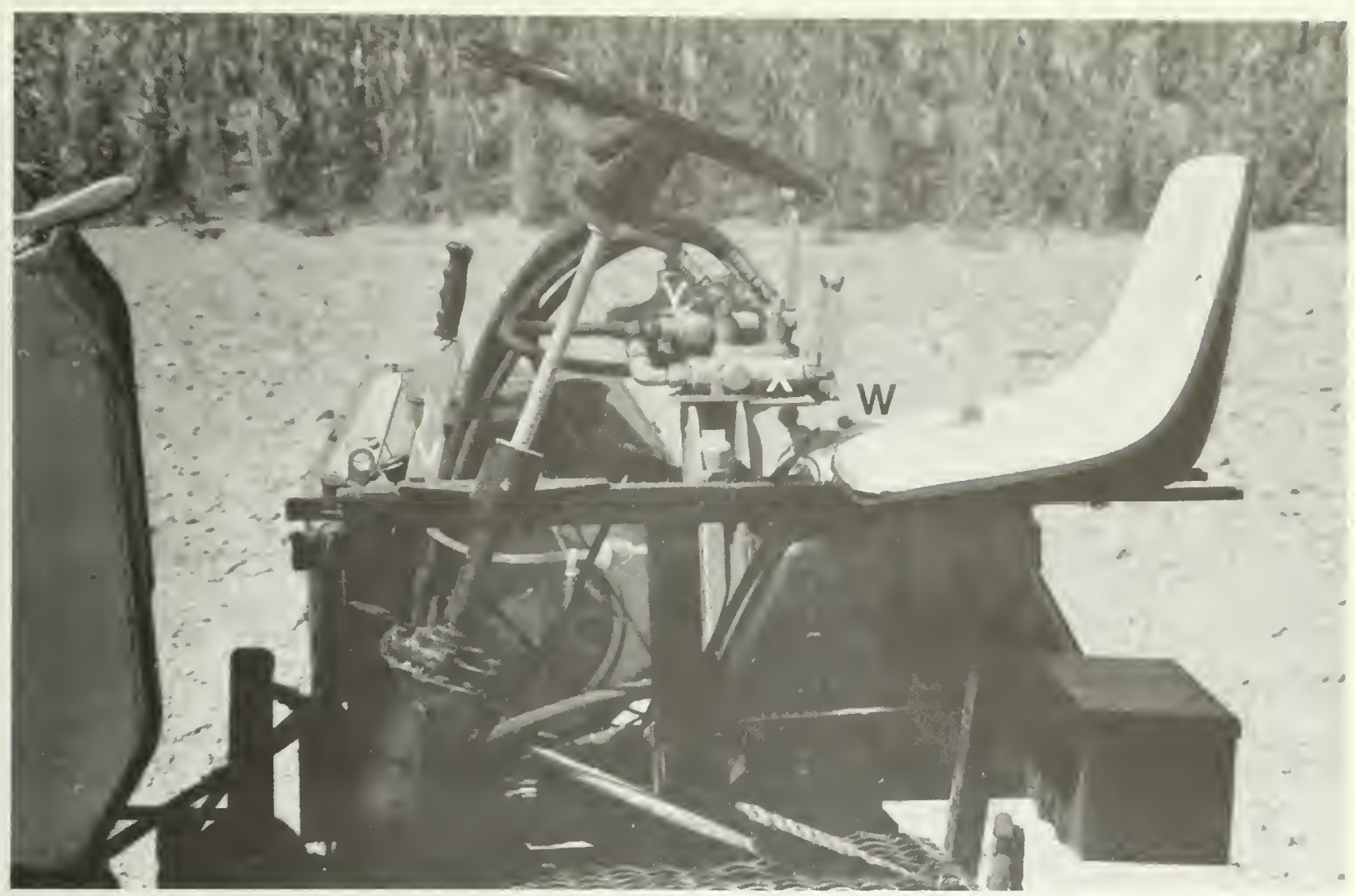

FIGURE 8 - Design of the control systems of the forage harvester.

The design of the control systems of the forage harvester is shown in Figure 8. The metal lever $V$ with a knob on top, located near the steering wheel, is used to engage and disengage the rotary cutter. The plate $W$ is a small dashboard with an ignition key unit, a choke control, and an ammeter. The throttle control is on the shaft supporting the steering wheel and the seat. The steering wheel operates the power steering control at the foot of the steering column, whereas the other hydraulic components are connected to two valves $X$ and $Y$ (Fig. 8) attached to the top of the hydraulic oil reservoir. The hydraulic valve $X$ is equipped with two double-action levers. One of these levers is used to open and close the gate of the hopper, and the other is used to lift the hopper and empty it, and bring it back to its original position. The hydraulic valve Y (Fig. 8) operates the cylinder control used to raise the front part of the forage harvester.

The transmission box is located under the motor support. The pedal Al (Fig. 9) is used to operate the idler pully F (Fig. 3), which puts tension on the belt to engage the transmission. The pedal BI (Fig. 9) is connected by a metal rod to a band brake attached to the transmission to stop the forage harvester.

\section{6 - THE CUTTER}

The front view of the forage harvester (Fig. 10) shows the cutter, which is 1 $\mathrm{m}$ wide and $45 \mathrm{~cm}$ in diameter in extension. A shaft $3.2 \mathrm{~cm}$ ( $11 / 4$ inches) in diameter covered by a cylinder of $10 \mathrm{~cm}$ ( 4 inches) makes up the core of the cutter. Attached to it are $9-\mathrm{cm}$ (3-1/2 inch) metal supports in pairs, to which the blades are fixed. 


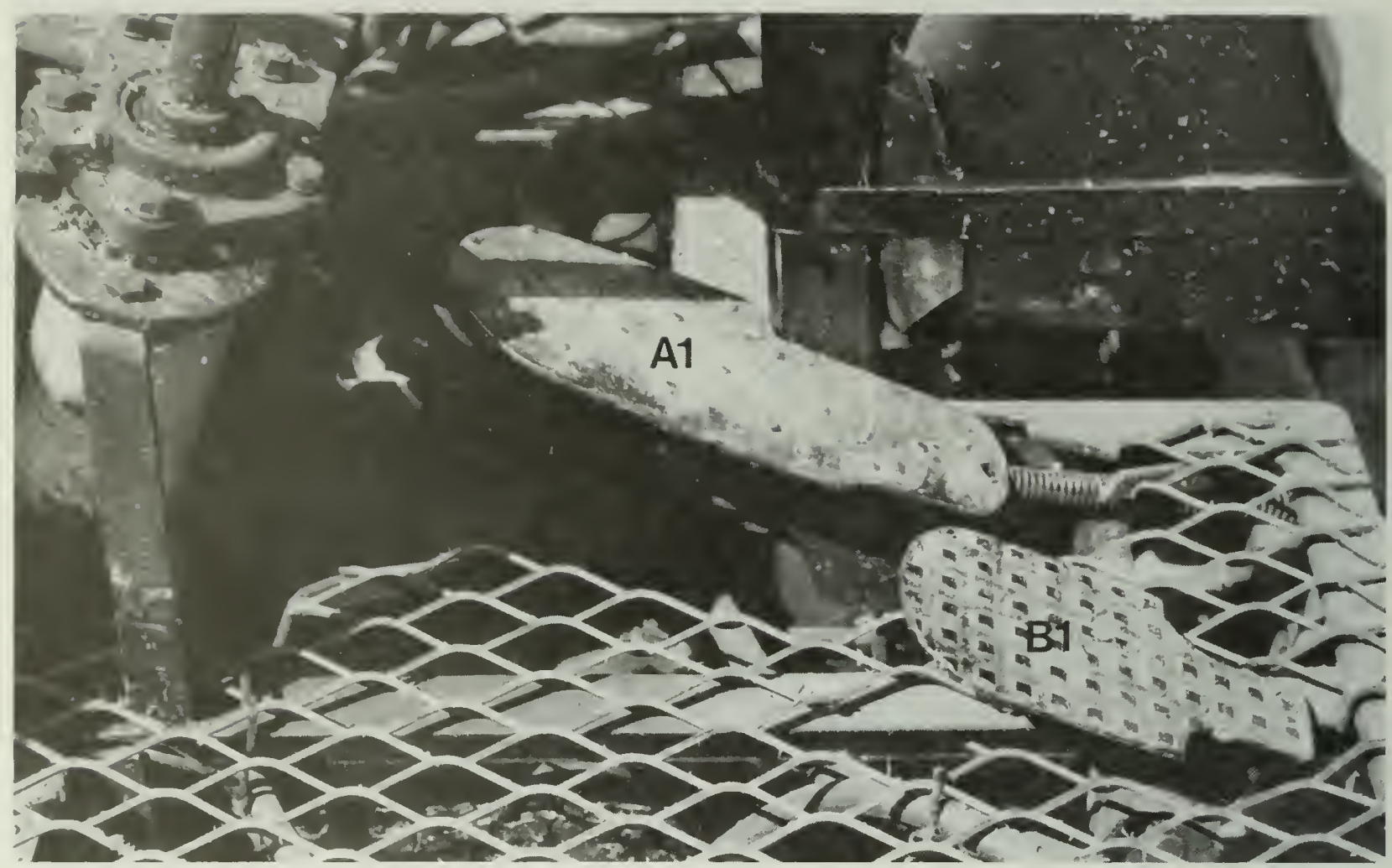

FIGURE 9 - Position of the clutch and brake pedals.

The blades are of the "Mott" type and are $3.2 \mathrm{~cm}$ ( 1 1/4 inches) wide by 12.5 $\mathrm{cm}$ ( 5 inches) long. An adjustable roller $10 \mathrm{~cm}$ ( 4 inches) in diameter is set beneath the back of the cutter to control the height of cut.

Two screens D1 and D2 (Fig. 10) with openings $1 \times 2 \mathrm{~cm}(3 / 8 \times 3 / 4$ inch) and $3 \times 16 \mathrm{~mm}(1 / 8 \times 5 / 8 \mathrm{inch})$ respectively are placed on the hopper to allow air to pass through and out.

\section{7 - HOPPER}

The frame of the hopper is made of square steel tubes, $2.5 \times 2.5 \mathrm{~cm}$ ( $1 \times 1$ inch). A metal sheet $1.56 \mathrm{~mm}$ (1/16 inch) thick is bent and welded inside the frame.

The interior dimensions and the gate, as well as the depth of the hopper, are shown in Figure 11. The gate moves on a large hinge. The capacity of the hopper cannot be determined from the dimensions as shown, because the open gate hides the upper part of the hopper (Fig. 14), which is $10 \mathrm{~cm}$ ( 4 inches) above the gate hinge. The capacity of the hopper is about 0.4 cubic metre ( 14 cubic feet).

\section{8 - OTHER ACCESSORIES}

A rear view of the forage harvester (Fig. 12) shows the location of other accessories such as the $12-\mathrm{V}$ battery (EI), the gas tank (Re), and the controls (Co) necessary for the operation of the harvester. 


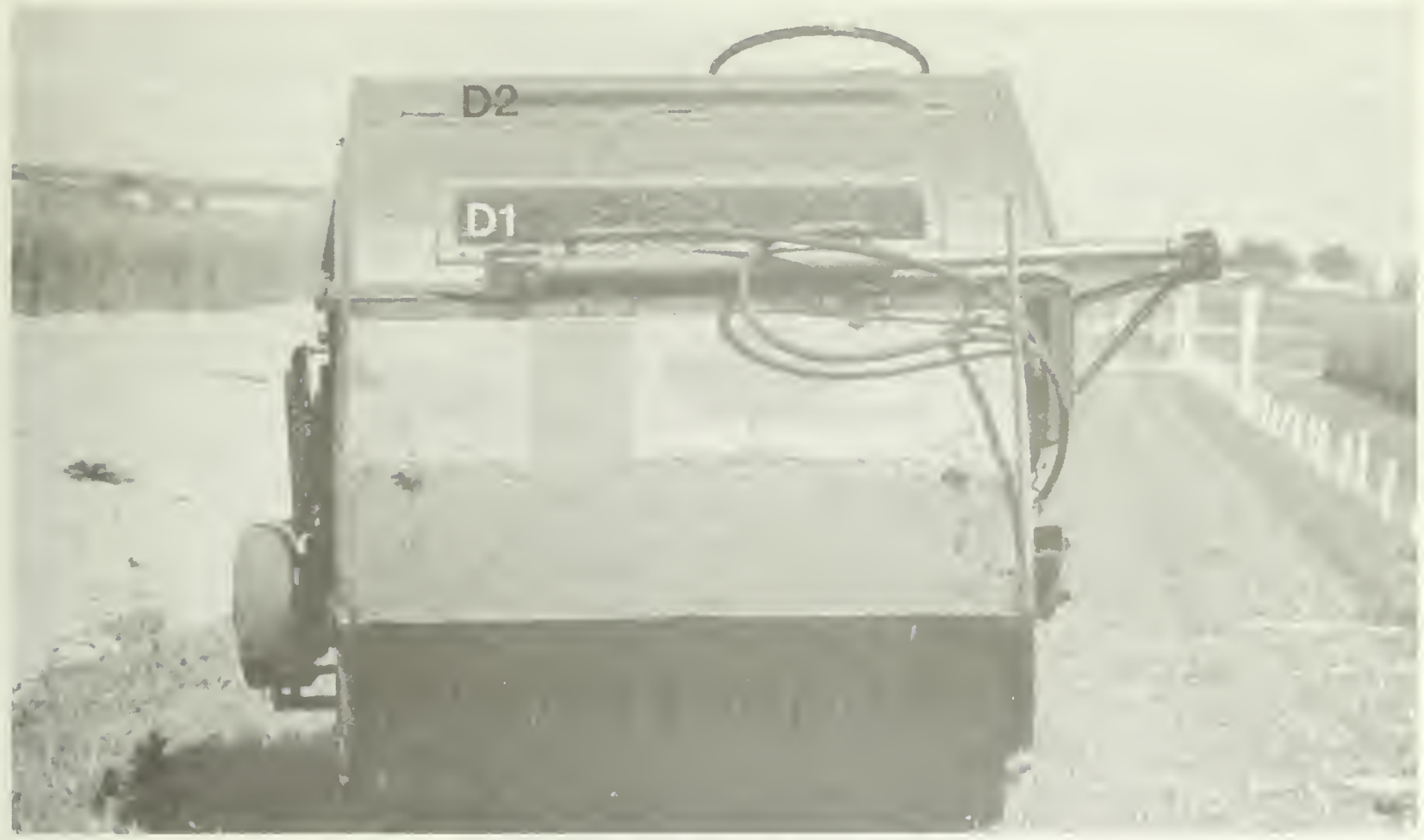

FIGURE 10 - Front view of the forage harvester showing the cutter.

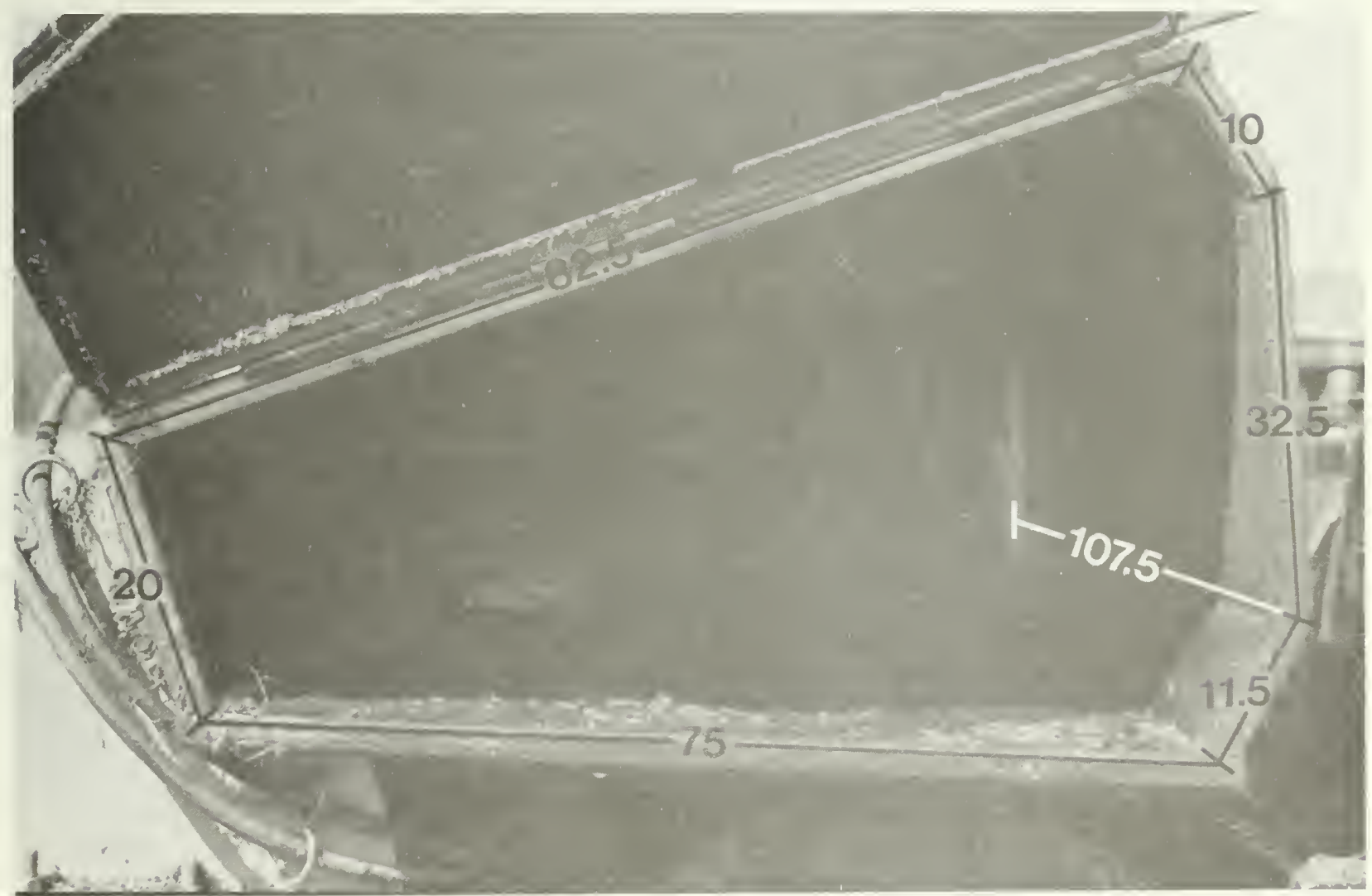

FIGURE 11 - Interior dimensions of the hopper in centimetres. 


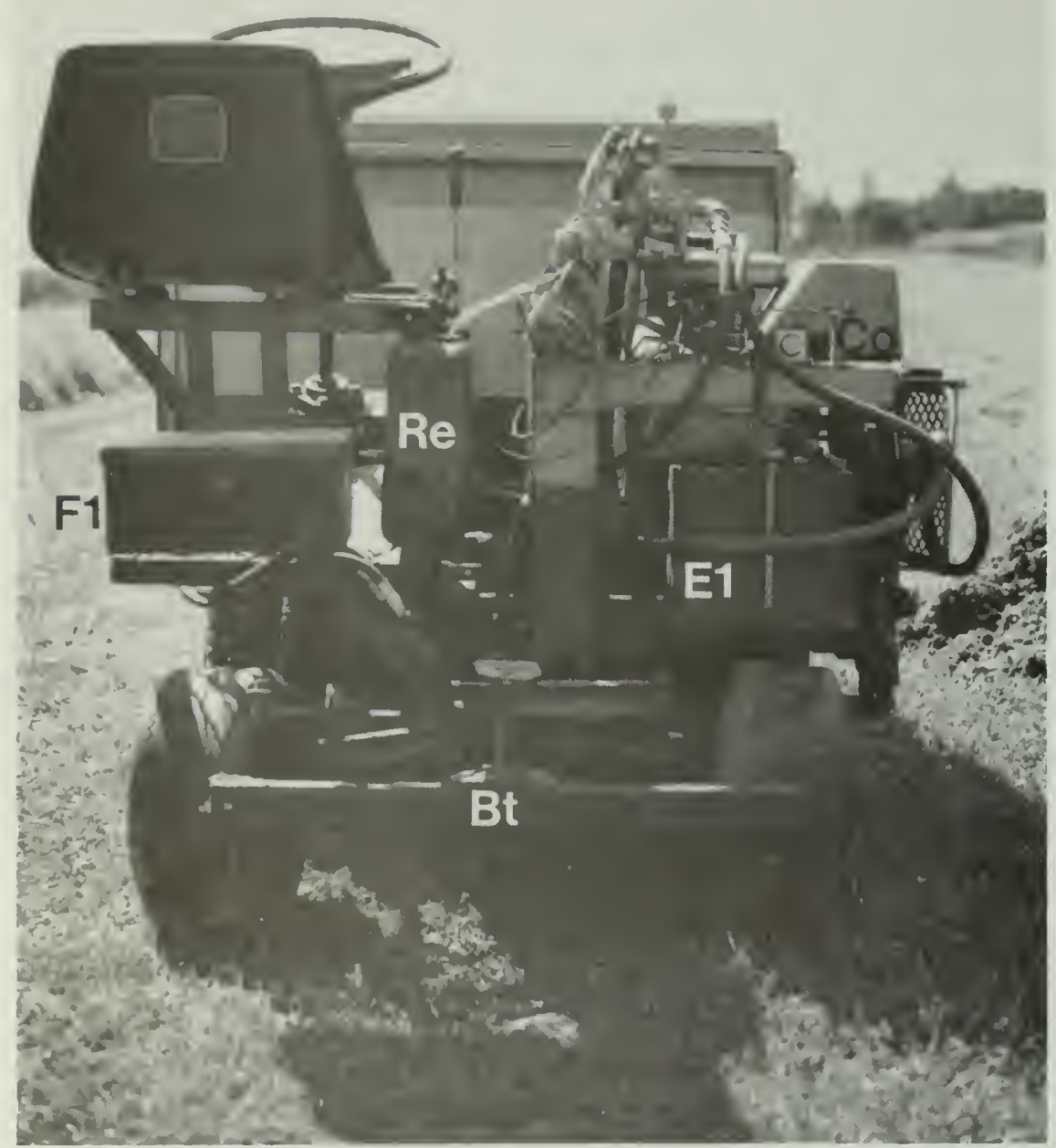

FIGURE 12 - Rear view of the forage harvester.

Other less important accessories have been added: a drawbar (Bt) and a toolbox (FI). The shape of the gas tank available allowed us to attach it to the support column of the seat and the steering wheel. However, any other models or shapes of gas tank could be installed by lengthening the footrest slightly toward the rear, without extending it beyond the vehicle frame, and by setting the gas tank partly under the seat in place of the toolbox.

\section{9 - SAFETY FEATURES}

The right side of the forage harvester (Fig. 13) shows the locations where the protective screens are installed. A screen Gl covers the motor tailpipe to prevent burns. Screens G2 and G3 protect the belt systems and minimize the possibility of injuries.

The left side view of the forage harvester (Fig. 14) shows the attachment of the roller (Ro) under the rear of the cutter and also the bolts used (Bo) to adjust the height of cut. A trapdoor ( $\mathrm{Tr}$ ) allows the operator to check the level of material in the hopper. 


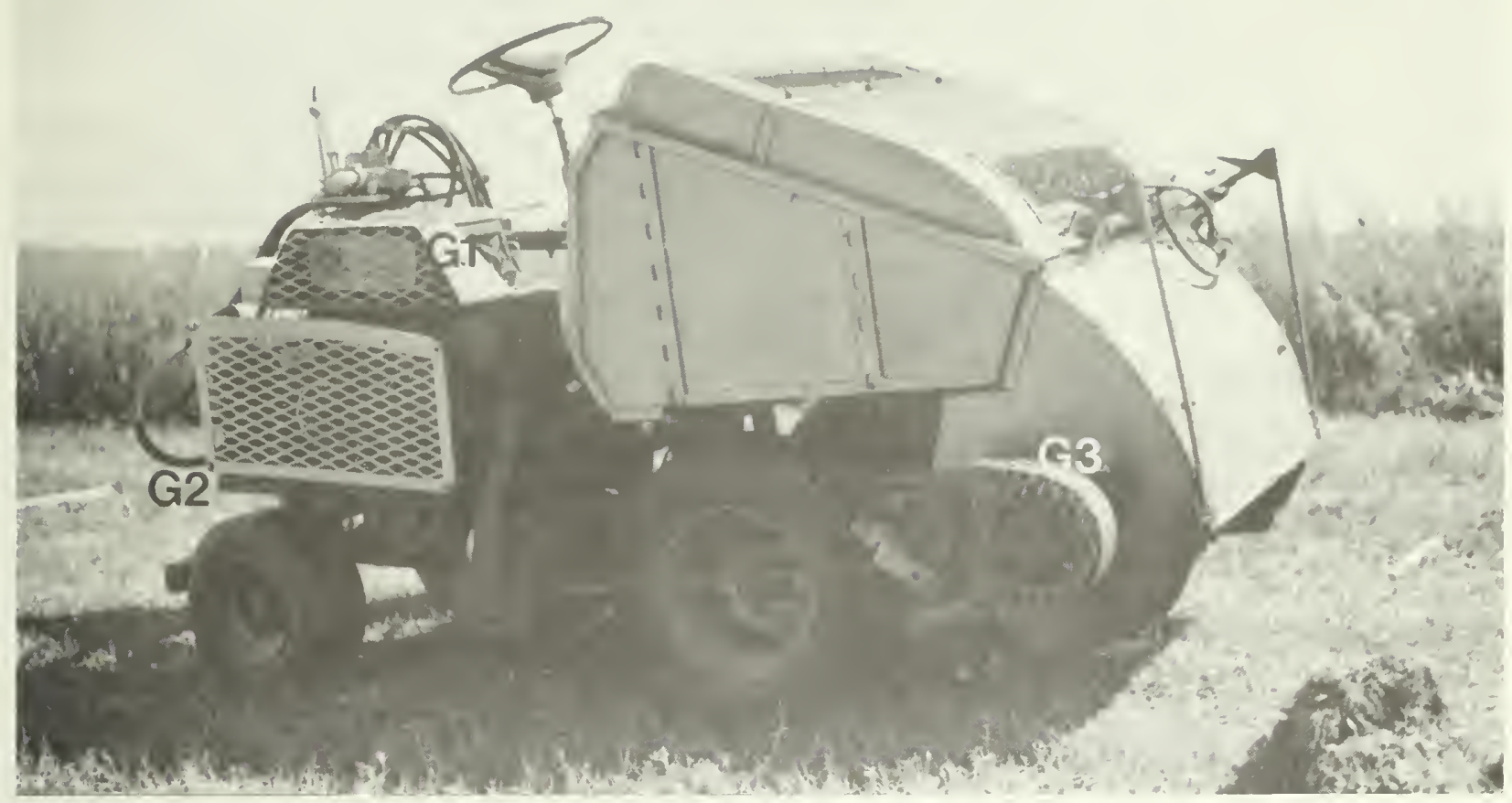

FIGURE 13 - Right side view of the forage harvester.

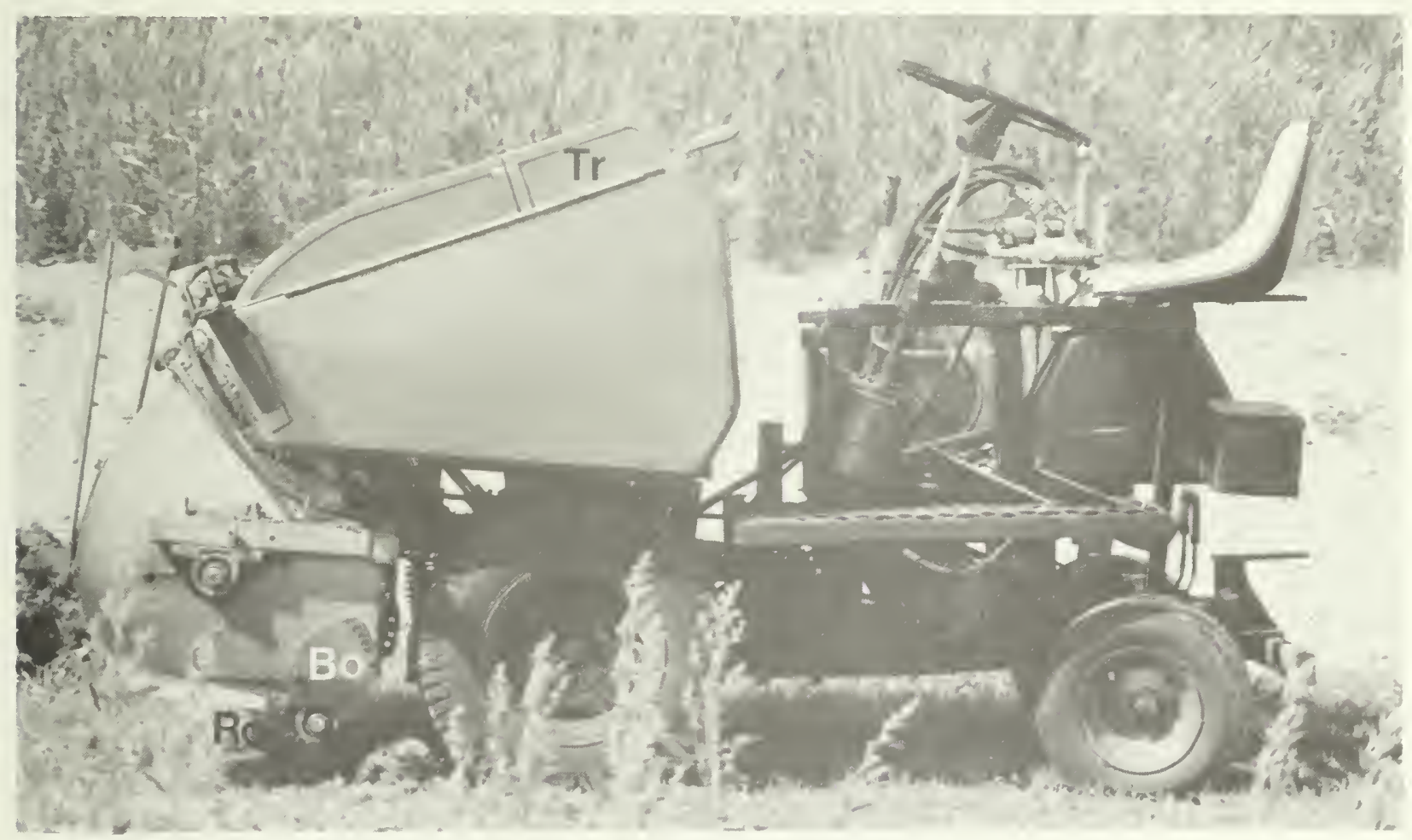

FIGURE 14 - Left side view of the forage harvester. 


\section{$2.10-$ CONCLUSION}

After 3 years, during which we tested, adjusted, and modified the forage harvester, we can confirm that it has attained its objectives. This very compact, large forage plot harvester can be transported long distances in the box of a truck or in a small trailer. We have been able to reduce hy one-third the time required to clean up test plots after harvesting. Also, the forage harvester can he used to take samples if the experiment requires data from large plots. The physical demands on the operator are minimal because all the controls are hydraulic, which permits the vehicle to be operated continuously for longer periods of time.

\subsection{1 - ACKNOWLEDGMENTS}

The authors wish to thank Drs. C. Gagnon and C. Richard for their advice in preparing this paper and Mr. J. St-Cyr, photographer and designer, for his collaboration in the photography. 
